\title{
Energy Efficiency of Chilled Water Pumping System Using Wireless Sensor Controller
}

\author{
Ignatius Widiatmoko Setiawan ${ }^{a^{*}}$, Rizal Broer Bahaweres ${ }^{b}$, Mudrik Alaydrus ${ }^{c}$ \\ ${ }^{\mathrm{a}, \mathrm{c}}$ Department of Electrical Engineering, Universitas Mercu Buana, Jakarta \\ ${ }^{\mathrm{b}}$ Department of Informatics, Faculty of Science and Technology, UIN Jakarta \\ *Email: setiawan.widi@yahoo.com
}

\begin{abstract}
One of the problem in chilled water pumping system is the degradation of performance of the control valve system that makes the energy consumption is less efficient. Thermomechanical method is proposed in this research to control the VSD of the pump to increase the energy efficiency of the pump. This method needs physical input references from the piping system using sensor that installed and connected to the main controller using wireless sensor network with Zigbee communication. This method was tested in the arduino prototype simulation. First simulation is simulated the less performance condition of the control valve and the result of the coefficient of performance (COP) is 1.07 with efficiency margin is $16.4 \%$. Second simulation is simulated the good performance condition and the result of the COP is 1.67 with efficiency margin is $37.2 \%$. From those result can be concluded that thermomechanical method can increase the energy efficiency if the control valve system is in the good performance condition. If the control valve system is less performance, this method can't give the energy efficiency as good as if the control valve at the good performance condition. Nevertheless, this method can increase the efficiency margin at the less performance condition of control valve.
\end{abstract}

Keywords: Chilled water pump, Energy efficiency, Wireless controller

\section{Introduction}

Air conditioning (AC) systems is a process to provide the conditions for human thermal comfort. Thermal Comfort is that condition of mind that expresses satisfaction with the thermal environment[1]. AC used should be get more attention because AC need a lot of energy consumption. One of the AC system that many used in the high rise building is Water Cooled Chilled Water System. How is water cooled chilled water system works, can be seen in the fig 1 . In the fig. 1 , we can see that there are an air handling unit (AHU) in each room (room 1, room 2 and room 3 ) that used to conditioned the room. Chilled water is produced by the chiller and distribute to every AHU using chilled water pump (CHWP). There is a control system that installed in the CHWP that make the CHWP is running to suite with the actual AC load to get more efficient of energy consumption of the CHWP. Many method are used to controlled the CHWP, one of the method is sensorless Variable Speed (VSD) pump.

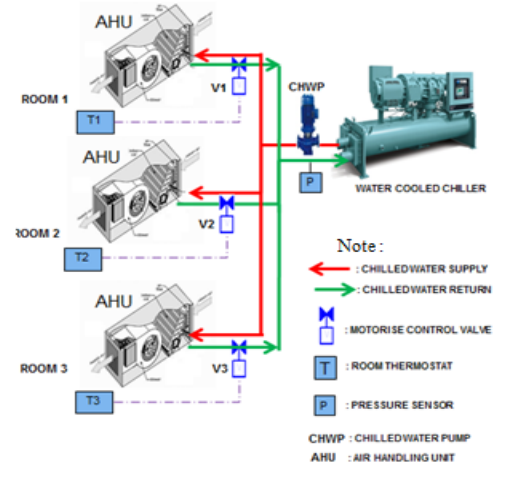

Fig. 1. Water Cooled Chilled Water System

Room thermostat was installed in every room to adjust the room temperature set point. When the room temperature is achieve to the temperature set point, the thermostat will send signal to motorise control valve and the control valve will be closed so the chilled water supply to AHU will be shut off and the chilled water pressure in the system will be increase. This pressure increment will be detect by sensorless VSD controller and then the controller will reduce the speed of the CHWP to suite with the chilled water flow requirement. The variable speed drive concept uses an inverter to supply the motor with enough energy to turn the shaft at the speed and torque the application requires [2].

Many case happen in the building is when the AC load is various up and down, the chilled water pressure in the piping system is still constant. Its indicate that the CHWP is running constantly and indicate that there is a waste energy used to operate the pump because pump delivered more chilled water than the required. The main concern of this research is how to increase the energy efficiency of chilled water pumping system shown on the figure 1 and how much the efficiency achievement with the proposed method.

Many research about pump energy efficiency already done in previous. Pump speed controller is used to control the water flow base in the system requirement to increase the pump energy efficiency. In [3], to reduce the control problem because of the sensor malfunction and poor maintenance of the system, sensorless pump controller is proposed. The method in this research is using Affinity transformation of Bernoulli equations to determine the pump speed base on the flow requirement. PLC is used for data processing and the result of the algorithm is use to control the pump speed. The other method is proposed in [5]. Combination method between mathematics and physic model is use to control the pump speed. Affinity 
transformation of Bernoulli equations is used to determine the speed required base on the actual torque and combine with speed sensor, pressure sensor and torque sensor for the physic model. The result in the [5] is the system have more flexibility and accurate in the static and dynamic condition.

\section{Research Method}

\section{A. System Modeling}

Simulation model of the chilled water system condition will be use in this research. The system modeling is shown in the figure 2 .

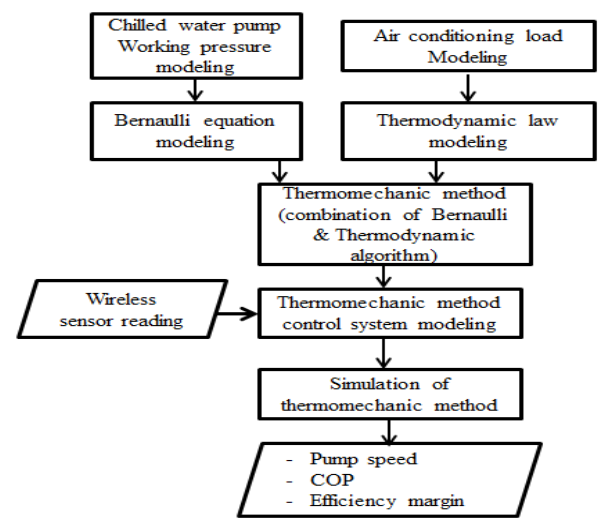

Fig. 2. Flowchart of the system modeling

\section{B. Chilled Water Pump working pressure modeling}

Chilled water flow rate in every AHU is controlled by motorised control valve that the control valve is controlled by room thermostat. Control valve will open and close refer to the room temperature. In condition that the chilled water piping is fixed size, the opened and closed of the control valve caused the pressure of the chilled water in the piping will be fluctuated. Chilled Water Pump working pressure model is shown in figure 3.

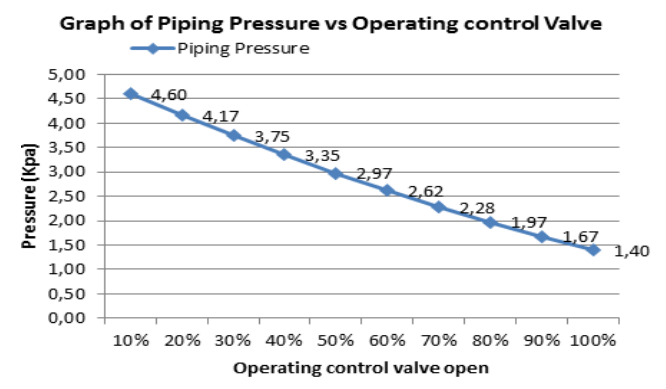

Fig. 3. Chilled water pump working pressure model

\section{Bernoulli equation modeling}

Centrifugal pumps are the most common type of pumps found in industrial applications[14], also for the chilled water pumping system. In a centrifugal pump, the energy of the fluid is increased by increasing the flow velocity with a rotating impeller, which generates the fluid flow[3]. Impeler is the component in the centrifugal pump that rotated by a motor to convert the motor energy become fluid energy that able to discharge the fluid[4]. Most of pumping applications can be defined as the level control and the pressure control systems. Typically, both of them require pressure detection. Pressure control applications have the following principle of operation. The system tends to keep pressure on a desired level. The speed of a pump is changing according to some Actual Value - Set-Point[3].

The head and the pressure alter with the squared pump speed as follows [3] :

$$
\mathrm{H} 2=\mathrm{H} 1 \times\left(\frac{\mathrm{n} 2}{\mathrm{n} 1}\right)^{2} \mathrm{H} 2=\mathrm{H} 1 \times\left(\frac{\mathrm{n} 2}{\mathrm{n} 1}\right)^{2}
$$

The power varies with the cube of the pump rotational speed as follows[3]:

$$
\mathrm{P} 2=\mathrm{P} 1 \times\left(\frac{\mathrm{n} 2}{\mathrm{n} 1}\right)^{3} \mathrm{P} 2=\mathrm{P} 1 \times\left(\frac{\mathrm{n} 2}{\mathrm{n} 1}\right)^{3}
$$

To govern the relationships between the pressure (p) variables at the changing pump speed $n$, every hydraulic system is described with the affinity laws[5]:

$$
\frac{\mathrm{H} 1}{\mathrm{H} 2}=\frac{\mathrm{p} 1}{\mathrm{p}_{2}}=\left(\frac{\mathrm{n} 1}{\mathrm{n} 2}\right)^{2} \frac{\mathrm{H} 1}{\mathrm{H} 2}=\frac{\mathrm{p} 1}{\mathrm{p}_{2}}=\left(\frac{\mathrm{n} 1}{\mathrm{n} 2}\right)^{2}
$$

With the pump speed will be controlled in the certain pressure, so the speed required (n2) can be determined from (3) as follows :

$$
\mathrm{n} 2=\mathrm{n} 1 \times \sqrt{\frac{\mathrm{p} 1}{\mathrm{p} 2}} \mathrm{n} 2=\mathrm{n} 1 \times \sqrt{\frac{\mathrm{p} 1}{\mathrm{p} 2}}
$$

where :

H1 : pump head at duty point, (m) (m)

$\mathrm{H} 2$ : actual pump head when the system is running

p1 : pressure set point (m)

p2 : actual pressure when system is running (m)

P1 : power at p1 (watt)

P2 : power at p2 (watt)

n1 : pump speed at duty point (rpm)

n2 : actual pump speed required (rpm)

Chilled water pump characteristic that will be modeled is shown on the fig. 4. Pump curve on fig. 4 is base on the factory pump selection for Grundfos pump series $97568233 \mathrm{CME} 1-4.60 \mathrm{~Hz}$. Base on this curve, the duty point of the pump is (Q1) $10 \mathrm{l} / \mathrm{min}$ flow rate at the pump head (H1) is $10 \mathrm{~m}$ with the pump speed (n1) is $1664 \mathrm{rpm}$.
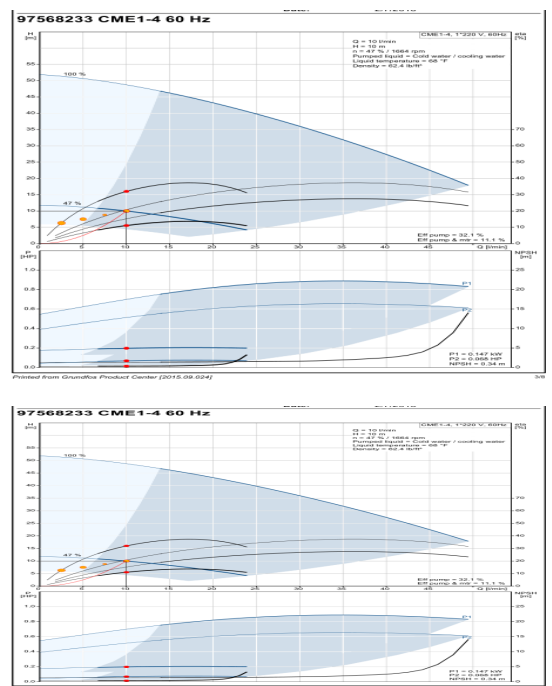

Fig. 4. Pump curve selection 


\section{Air conditioning load and Thermodynamic modeling}

Beside the change of the pressure in the pipeline, the other physical characteristic that can be observed in the chilled water system is the change of the heat load. Refer to the first law of thermodynamic, heat can be defined as amount of energy that transfer from one object to the others which have lower temperature[6]. The heat transfer can determine as follows [6]:

where :

$$
\mathrm{Q}=\mathrm{m}^{\circ} \times \mathrm{Cp} \times \Delta \mathrm{T}
$$

Q : heat transfer, KW (kilowatt)

$\mathrm{m}^{\circ} \quad$ : fluid flow rate, $\mathrm{Kg} / \mathrm{s}$

$\mathrm{Cp} \quad$ : specific heat of the fluid, $\mathrm{KJ} / \mathrm{Kg} . \mathrm{K}$

: Temperature different, $\mathrm{K}$

$\Delta \mathrm{T}=\mathrm{T} 2-\mathrm{T} 1$

T2 : end of temperature, $\mathrm{K}$

$\mathrm{T} 1$ : initial Temperature, $\mathrm{K}$

There is 2 way to adjust the chilled water flow rate. Ones is adjustment base on the pressure set point an the others is base on the $\Delta \mathrm{T}$ set point. To get the flow rate required base on the actual heat load in the (5), needs input of actual flow rate and actual $\Delta \mathrm{T}$ from the system. For the specific heat of the water is taken from the average of $4.2 \mathrm{KJ} / \mathrm{Kg} . \mathrm{K}[7]$. Air conditioning load modeling is shown in fig. 5. Refer to (5) can be seen that amount of heat transfer is proportional with the flow rate.

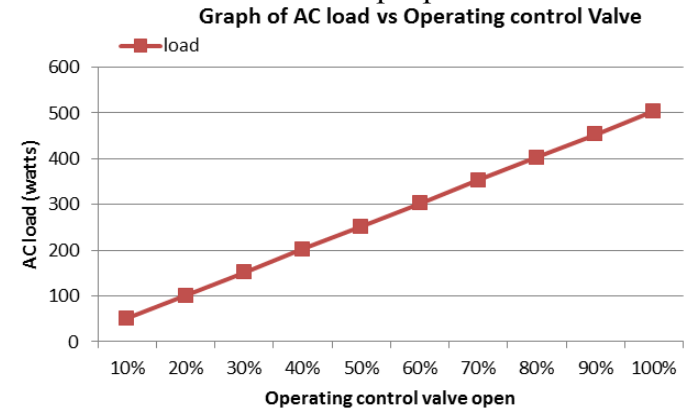

Fig. 5. Air conditioning load modeling

So the conjunction between the change of flow rate and pump speed as follows:

$$
\frac{\mathrm{m}^{1} 1}{\mathrm{~m}^{\circ} 2}=\frac{\mathrm{n} 1}{\mathrm{n} 2} \frac{\mathrm{m}^{1} 1}{\mathrm{~m}^{\circ} 2}=\frac{\mathrm{n} 1}{\mathrm{n} 2}
$$

where :

$\mathrm{m}^{\circ} 1$ : actual flow rate at duty point, $\mathrm{Kg} / \mathrm{s}$

$\mathrm{m}^{\circ} 2$ : flow rate required at certain heat load, $\mathrm{Kg} / \mathrm{s}$

with the flow rate is proportional with heat load, the pump speed refer to change of heat load can defined from (9) as follow :

$$
\frac{\mathrm{Q} 1}{\mathrm{Q} 2}=\frac{\mathrm{n} 1}{\mathrm{n} 2} \frac{\mathrm{Q} 1}{\mathrm{Q} 2}=\frac{\mathrm{n} 1}{\mathrm{n} 2}
$$

So the required pump speed $(\mathrm{n} 2)$ is :

$$
\mathrm{n} 2=\frac{\mathrm{Q}_{2}}{\mathrm{Q}_{1}} \times \mathrm{n} 1 \mathrm{n} 2=\frac{\mathrm{Q}_{2}}{\mathrm{Q}_{1}} \times \mathrm{n} 1
$$

where :

Q1 : Load at duty point (watts)

Q2 : Actual load (watts)

\section{E. Propose Method}

This paper proposed Thermomechanical method to control the chilled water pump speed. Thermomechanical method is combining the bernoulli laws (refer to [3] and
[5]) to determine the pump speed required base on the pressure changing and the thermodynamic law to determine the pump speed required base on the AC load changing. The flowchart of thermomechanical method is shown in fig. 6 .

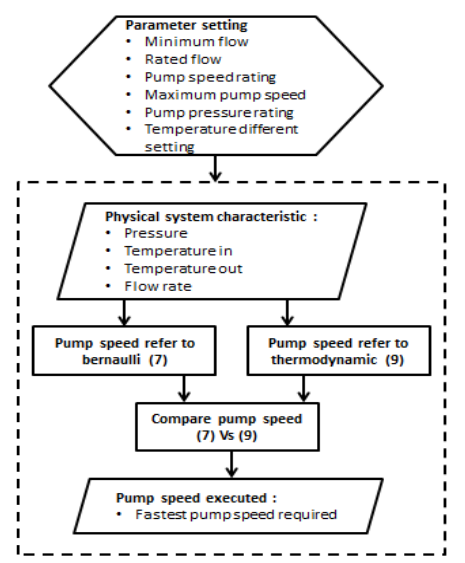

Fig. 6. Flowchart of Thermomechanical method

F. Thermomechanical method control system modeling

There is a simulation model is needed to test the thermomechanical method. The simulation is simulated the changes of the chilled water physical characteristic that are temperature, pressure, water flow rate and $\mathrm{AC}$ load where this characteristic will be use as the input of the processing unit and then the output will be use to adjust the CHWP speed. This control simulation model is represent the condition of the chilled water system that will be simulated. The design prototype of the model is shown in fig. 7 and consist of chilled water piping design and control system design.

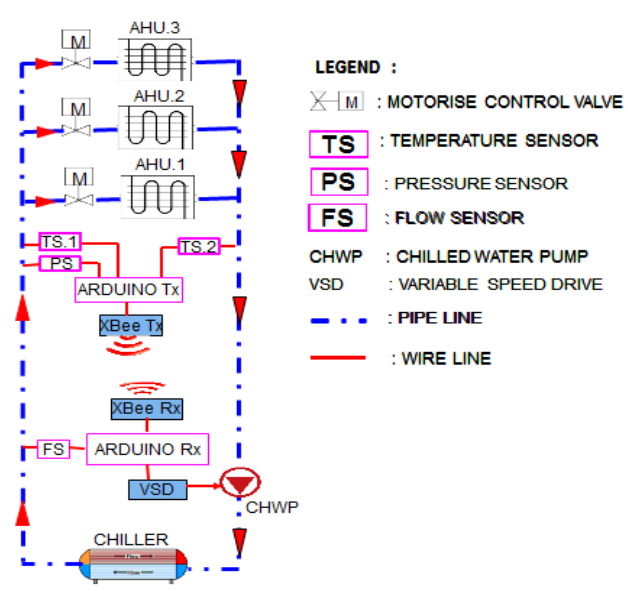

Fig. 7. Design Prototype of chilled water piping and control system

\section{G. Chilled water piping design}

In this research, the chilled water piping is not physically build. The piping is simulated base on the changes of physical characteristic of chilled water that are changes of flow rate, pressure and temperature. This characteristic changing will be simulated base on set point parameter that already determined base on the size of the piping system prototype. The changes of the physical characteristic of the pump is refer to the fig. 3. To determine the pressure set point is assumed that the AHU operation redundancy is $70 \%$. Base on the graph in fig. 3 , the set pressure $(\mathrm{p} 1)$ is $2.28 \mathrm{Kpa}$. The temperature 
different set point $(\Delta \mathrm{T} 1)$ is $6{ }^{\circ} \mathrm{C}$ which the chilled water temperature in is $6{ }^{\circ} \mathrm{C}$ and the chilled water temperature out is $12{ }^{\circ} \mathrm{C}$. The chilled water flow rate range is between 0 until $20 \mathrm{l} / \mathrm{min}$ with the pump speed range is from $0 \mathrm{rpm}$ to $2550 \mathrm{rpm}$.

\section{H. Control system design}

Input data reading from the system is needed to implement the thermomechanical method control system. This data is coming from the sensor reading and consist of flow rate, chilled water temperature in, chilled water temperature out and chilled water pressure. From the sensor, the data is transmitted to the controller and processed by the controller to determine the output to control the pump speed. One of the method to transmit the data to the controller is using Wireless Sensor Network (WSN). Some of the wireless communication that used in WSN are IEEE 802.11 (WLAN), IEEE 802.15.1 (Bluetooth) and IEEE 802.15.4 (ZigBee)[9]. From the power consumption side, Zigbee is the lowest energy consumption. And for the number of nodes connection, Zigbee is the wireless communication with most number of nodes connected. In the [9], Zigbee is used and the result is that the data error is better than the wired connection because Zigbee is more resistance to the magnetic field if compare to the wired communication. Regarding to the power consumption, in [10] is proposed to use Zigbee for home and the result is the system have more lifetime, durable and safety. WSN also have capability to do local computation so can send the only data needed rather than the raw data that not selected yet[11]. Refer to [9] and [10], in this paper is propose to use Zigbee communication to send the data reading from the temperature sensor and pressure sensor to the main controller. Wireless sensor network technical design basically consist of Hardware, software, system architecture and protocol and transmission media[12]. Control system installation in the chilled water piping system is shown in the fig.7. Arduino is use in this control system and its selected because cheap and easy for the configuration[13]. Zigbee component that used is Xbee S2. Prototype of transmitter and receiver node is shown in fig. 8 and fig. 9 .

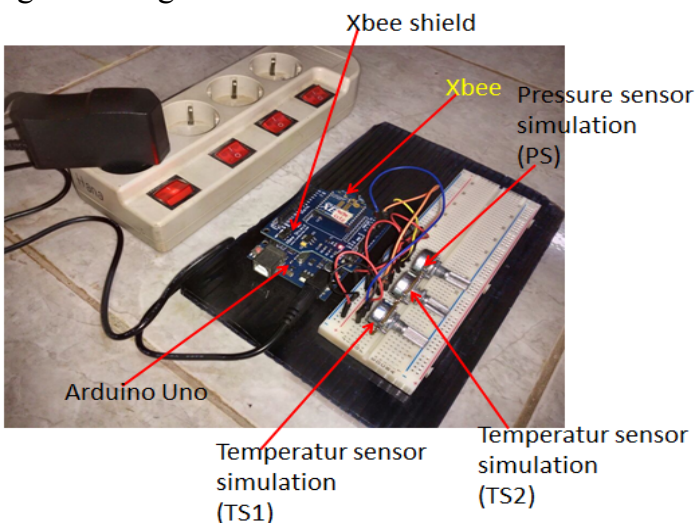

Fig.8. Prototype of Transmitter Node

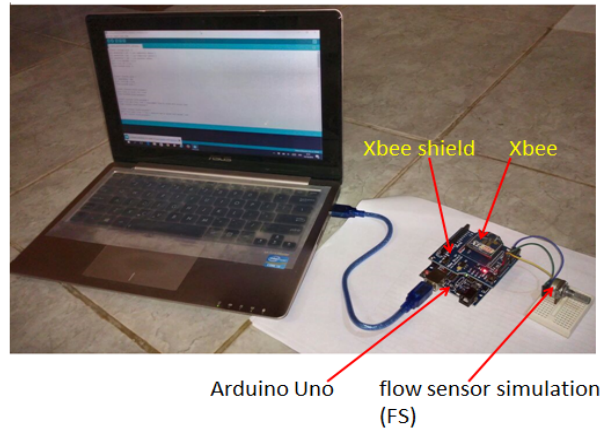

Fig.9. Prototype of Receiver Node

Simulation of the changes of temperature, pressure and flow rate of the chilled water will be done by the potentiometer. The simulation result will shown on the serial monitor that connected to the arduino using serial port in the laptop.

\section{Algorithm}

Flowchart of the thermomechanical algorithm that will be compiled into controller in fig. 10 and fig. 11. Fig. 10 is the wireless sensing algorithm of the temperature and pressure sensor reading. The flow process of the arduino base on the fig. 10 as follows:

1) Sensor will send the analog data reading which is temperature and pressure to arduino. This analog data is composed to arduino as digital reading with range of $0-1023$ that represent the voltage of $0-5 \mathrm{~V}$.

2) From this reading, arduino will do the simple computation to determine the $\Delta \mathrm{T}$ and then the result of the computation and the pressure reading will send to the Xbee receiver.

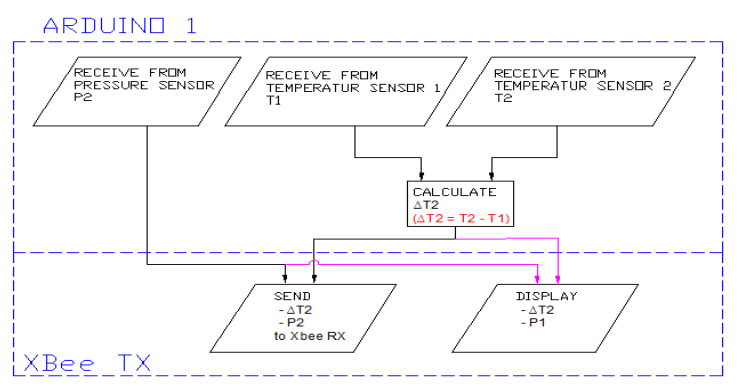

Fig. 10. Algorithm of Xbee Transmitter

Fig. 11 is the thermomechanical algorithm as on the propose method. The flow process of the Xbee receiver as fig. 11 as follows :

1) Set point parameter is inputted $i$ the arduino. This set point consist of minimum flow rate $\left(\mathrm{m}^{\circ} \mathrm{min}\right)$, set point of flow rate ( $\mathrm{m}^{\circ}$ rate), pump speed set point $(\mathrm{N} 1)$, pressure set point $(\mathrm{P} 1)$, temperature different set point $(\Delta \mathrm{T} 1)$ and specific heat of chilled water $(\mathrm{Cp})$.

2) Xbee $R x$ is received the data of pressure and $\Delta T$ that send by Xbee Tx and also the reading of flow rate from the flow sensor. This data will be process by arduino.

3) Arduino will calculate the actual load (Q1) at the system, and then determine the pump speed required (nA) base on the actual load.

4) From the pressure reading (p2), arduino will calculate the pump speed required (n $2 b)$ base on the changes of the pressure in the system. 
5) Arduino will compare between $\mathrm{nA}$ and $\mathrm{n} 2 \mathrm{~b}$ to determine the highest speed that will be executed to be the output as pump speed executed $(\mathrm{N})$.

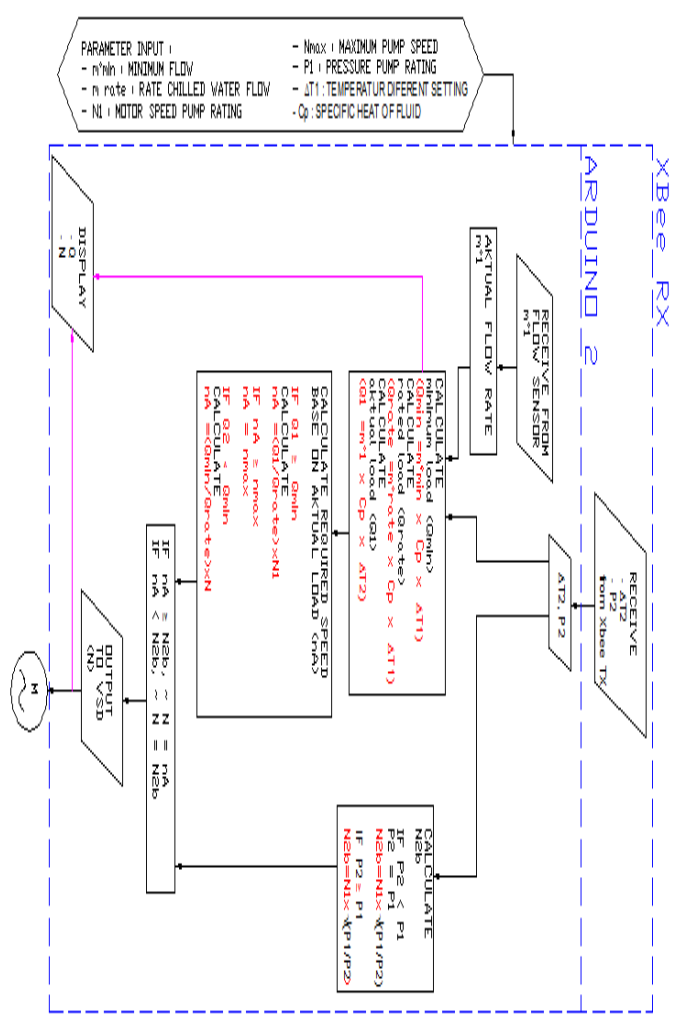

Fig. 11. Algorithm of Xbee Receiver

\section{Simulation}

System condition in figure 1 will be simulated in this research is shown in the fig. 12 .

\begin{tabular}{|l|l|l|l|l|l|l|l|}
\cline { 2 - 7 } \multicolumn{1}{c|}{} & T1 & T2 & T3 & V1 & V2 & V3 & P \\
\hline $\begin{array}{l}\text { Simulation 1 } \\
\text { (condition 1) }\end{array}$ & $\begin{array}{l}\text { achieve } \\
\text { set } \\
\text { point }\end{array}$ & $\begin{array}{l}\text { achieve } \\
\text { set } \\
\text { point }\end{array}$ & $\begin{array}{l}\text { below } \\
\text { set } \\
\text { point }\end{array}$ & Fail/open & Fail/open & open & constant \\
\hline $\begin{array}{l}\text { Simulation 2 } \\
\text { (condition 2) }\end{array}$ & $\begin{array}{l}\text { achieve } \\
\text { set } \\
\text { point }\end{array}$ & $\begin{array}{l}\text { achieve } \\
\text { set } \\
\text { point }\end{array}$ & $\begin{array}{l}\text { below } \\
\text { set } \\
\text { point }\end{array}$ & close & close & open & various \\
\hline
\end{tabular}

Fig. 12. Simulation Matrix of the chilled water system condition

$\begin{array}{ll}\text { T1, T2, T3 } & : \text { room thermostat } \\ \text { V1, V2, V3 } & : \text { motorised control valve } \\ \mathrm{P} & : \text { system pressure }\end{array}$

Set point : room temperature set point

\section{G. Simulation 1}

Refer to the simulation matrix in figure 12 , simulation 1 is represent the condition of the system when the room temperature is achieved and the thermostat send signal to motorise control valve to closed the valve, but that happen is the control valve is not fully close/fail. This condition makes the pressure in the system is still constant because the chilled water still trough in to the AHU. The simulation result are shown in fig. 13, 14 and 15. AC load profile is shown in fig. 13, pressure profile is shown in fig. 14 and the pump speed profile is shown in fig. 15 .
Air conditioning load Profile - simulation 1

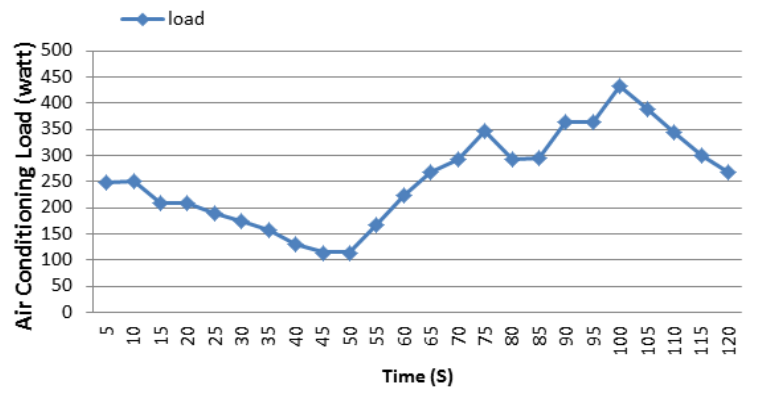

Fig. 13. Air Conditioning Load Profile at simulation 1

Pressure Profile - at Simulation 1

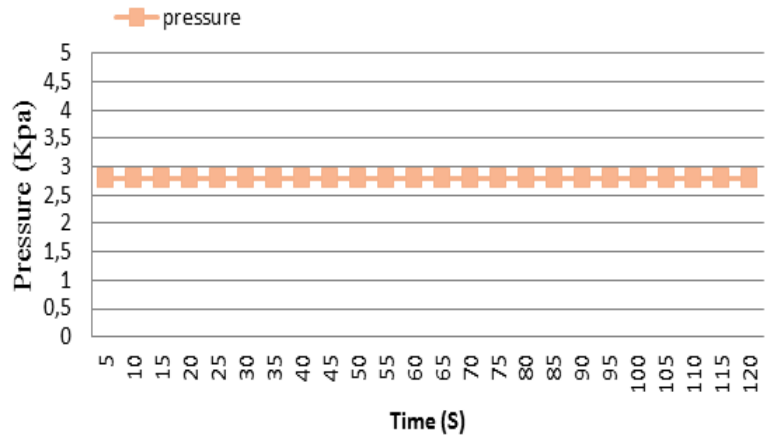

Fig. 14. Pressure profile at simulation 1

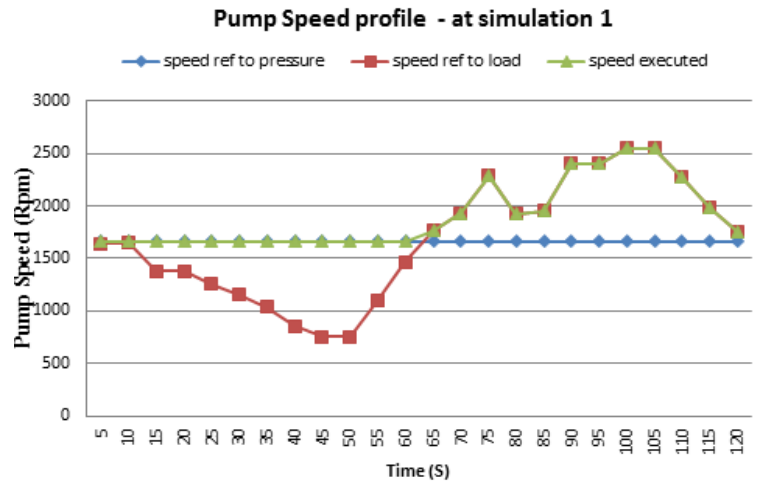

Fig. 15. Pump Speed Profile at simulation 1

Less performance condition of the control valve can be seen by compare the graph at the fig. 13 and fig. 14 . Fig. 13 is shown that the AC load is various, but because the control valve operation is failed so the pressure is still constant as shown in fig. 14. Pump speed profile is shown in fig. 15. The highest speed is selected as pump speed required and executed as actual pump speed.

\section{H. Simulation 2}

Refer to the simulation matrix in fig. 12, simulation 2 is represent the condition of the system when the room temperature is achieved and the motorise control valve is closed. This condition makes the pressure in the system is various as shown in fig. 3. The simulation result are shown in fig. 16,17 and 18. AC load profile is shown in fig. 16, pressure profile is shown in fig. 17 and the pump speed profile is shown in fig. 18. Good performance condition of the control valve can be seen by compare the graph at the fig. 16 and fig. 17. Fig. 16 is shown that the $\mathrm{AC}$ load is various, and because of the control valve operation is performed so the pressure is various also as shown in fig. 17. Pump speed profile is shown in fig. 18. 
The highest speed is selected as pump speed required and executed as actual pump speed.

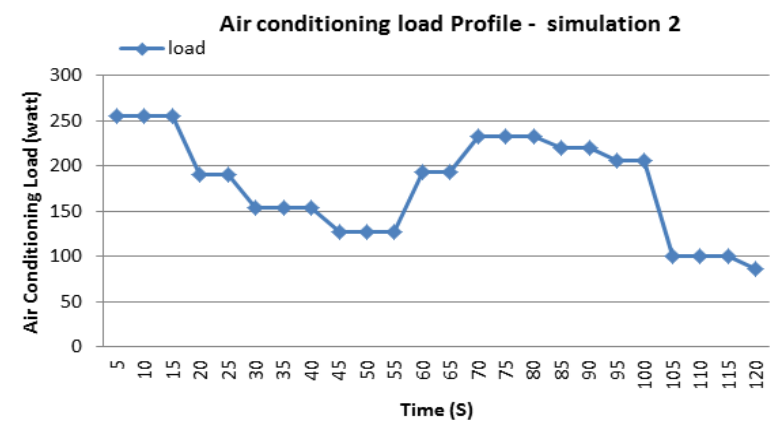

Fig.16. Air Conditioning Load Profile at simulation 2

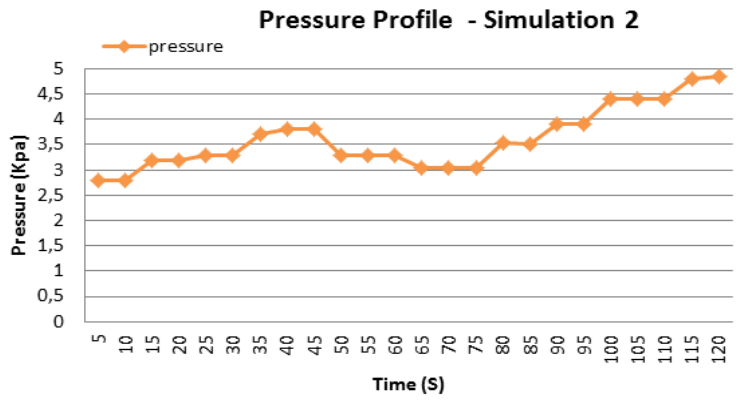

Fig. 17. Pressure Profile at simulation 2

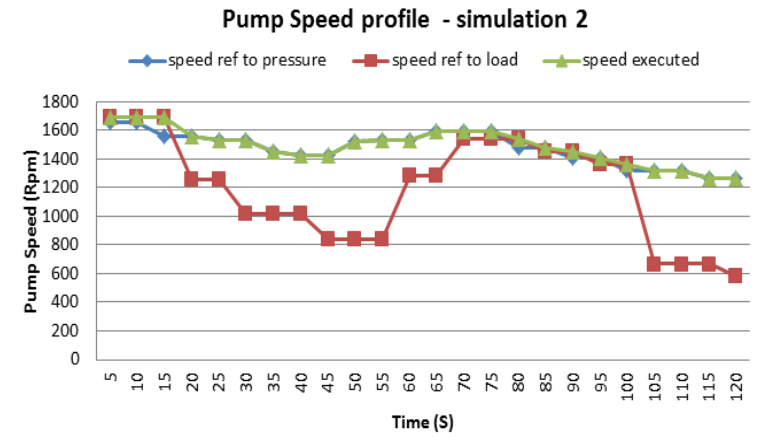

Fig. 18. Pump Speed Profile at simulation 2

\section{Data Analysis}

The energy used of cooling equipment mainly depends on the characteristic of the refrigerant system. For chilled water system, the centrifugal chiller assumed the energy use is $0.55 \mathrm{KW} / \mathrm{TR}(6.39 \mathrm{COP})$ and the water pump is 0.2 $\mathrm{KW} / \mathrm{TR}$ (17.6 COP) [16]. Coefficient of performance (COP) and efficiency margin is needed to analysis how much the thermomechanical method can increase the energy efficiency of the chilled water system. COP is the comparison between the actual result capacity and the power consumption needed. COP is define as follows[1] :

$$
\mathrm{COP}=\frac{\mathrm{Qr}_{\mathrm{r}}}{\mathrm{PC}_{\mathrm{C}}} \mathrm{COP}=\frac{\mathrm{Qr}}{\mathrm{Pc}_{\mathrm{c}}}
$$

where :

Qr : actual heat load (watt. hour)

Pc : total Power consumption (watt.hour)

And the efficiency margin $(\eta \mathrm{m})$ is :

$$
\begin{gathered}
\frac{\Delta \mathrm{COP} \eta \mathrm{m}}{\mathrm{COP} \text { ref to Load }} \times 100 \% \\
\Delta \mathrm{COP}=\mathrm{COP} \text { ref to Load - actual COP }
\end{gathered}
$$

The power input adjustment base on the changes of the pump speed is define as [5]:

$$
\frac{\mathrm{PI} 1}{\mathrm{PI} 2}=\left(\frac{\mathrm{N} 1}{\mathrm{~N} 2}\right)^{3} \frac{\mathrm{PI} 1}{\mathrm{PI} 2}=\left(\frac{\mathrm{N} 1}{\mathrm{~N} 2}\right)^{3}
$$

where :

PI1 : motor pump power input at rated speed (watt)

PI2 : motor pump power input at speed executed (watt)

N1 : pump speed at rated speed (Rpm)

N2 : pump speed at speed executed (Rpm)

So PI2 is :

$$
\mathrm{PI} 2=\frac{\mathrm{PI} 1}{(\mathrm{~N} 1 / \mathrm{N} 2)^{3}} \mathrm{PI} 2=\frac{\mathrm{PI} 1}{(\mathrm{~N} 1 / \mathrm{N} 2)^{3}}
$$

With the Qr and Pc is define as follows :

$$
\begin{aligned}
& \mathrm{Qr}=\sum \text { loadQ } \mathrm{r}=\sum \text { load } \\
& \mathrm{Pc}=\sum \mathrm{PI} 2 \mathrm{Pc}=\sum \mathrm{PI} 2
\end{aligned}
$$

The analysis result is shown in the table 1 and table 2 . Table 1 shown the actual load (Qr) is 6141 watt.hours, the total power consumption refer to the actual load is 4786 watt.hours, and total of actual power consumption that executed is 5759 watt hours. So the comparison of expected COP (ref to load) and the actual COP as shown in fig. 19 is determine use (9) formula.

\section{COP comparison - simulation 1}

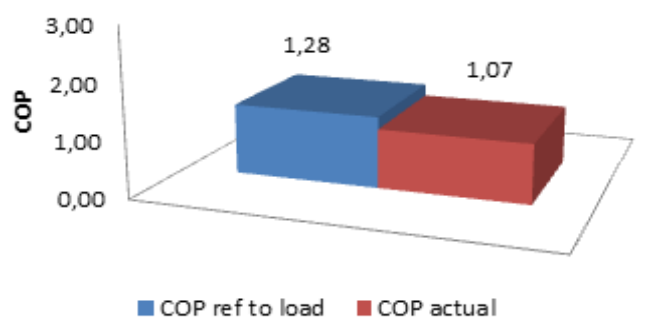

Fig. 19. Comparison of expected COP vs Actual COP at simulation 1

Table 1. Analysis result at Simulation 1

\begin{tabular}{|c|c|c|c|c|c|}
\hline $\begin{array}{c}\text { Time } \\
\text { (S) }\end{array}$ & $\begin{array}{c}\text { Load } \\
\text { (watt } \\
\text { ) }\end{array}$ & $\begin{array}{c}\text { speed ref } \\
\text { to load } \\
\text { (Rpm) }\end{array}$ & $\begin{array}{c}\text { Speed } \\
\text { executed } \\
\text { (Rpm) }\end{array}$ & $\begin{array}{c}\text { PI ref to } \\
\text { load } \\
\text { (watt) }\end{array}$ & $\begin{array}{c}\text { PI } \\
\text { excecuted } \\
\text { (watt) }\end{array}$ \\
\hline 5 & 249 & 1643 & 1664 & 142 & 147 \\
\hline 10 & 250 & 1649 & 1664 & 143 & 147 \\
\hline 15 & 209 & 1381 & 1664 & 84 & 147 \\
\hline 20 & 209 & 1381 & 1664 & 84 & 147 \\
\hline 25 & 190 & 1256 & 1664 & 63 & 147 \\
\hline 30 & 174 & 1152 & 1664 & 49 & 147 \\
\hline 35 & 157 & 1037 & 1664 & 36 & 147 \\
\hline 40 & 130 & 857 & 1664 & 20 & 147 \\
\hline 45 & 114 & 753 & 1664 & 14 & 147 \\
\hline 50 & 114 & 753 & 1664 & 14 & 147 \\
\hline 55 & 166 & 1097 & 1664 & 42 & 147 \\
\hline 60 & 222 & 1468 & 1664 & 101 & 147 \\
\hline 65 & 267 & 1763 & 1763 & 175 & 175 \\
\hline 70 & 293 & 1932 & 1932 & 230 & 230 \\
\hline 75 & 347 & 2290 & 2290 & 383 & 383 \\
\hline 80 & 292 & 1926 & 1926 & 228 & 228 \\
\hline 85 & 296 & 1952 & 1952 & 237 & 237 \\
\hline 90 & 364 & 2406 & 2406 & 444 & 444 \\
\hline 95 & 364 & 2406 & 2406 & 444 & 444 \\
\hline 100 & 433 & 2550 & 2550 & 529 & 529 \\
\hline 105 & 389 & 2550 & 2550 & 529 & 529 \\
\hline 110 & 344 & 2271 & 2271 & 374 & 374 \\
\hline 115 & 301 & 1985 & 1985 & 250 & 250 \\
\hline 120 & 267 & 1754 & 1754 & 172 & 172 \\
\hline TOTAL & 6141 & & & 4786 & 5759 \\
\hline & & & & & \\
\hline
\end{tabular}


Fig. 19 shown that the expected COP is 1.28 but the actual COP is 1.07. There is a gap between the expected and the actual COP that called efficiency margin, calculate with formula (10) the efficiency margin is $16.4 \%$. The result of the thermomechanical method in the normal condition as simulated on the simulation 2 can be seen in table 2. Table 2 shown the actual load (Qr) is 4314 watt.hours, the total power consumption refer to the actual load is 1619 watt.hours, and total of actual power consumption that executed is 2585 watt hours. So the comparison of expected COP (ref to load) and the actual COP as shown in fig. 20 is determine use (9) formula. Fig. 22 shown that the expected COP is 2.66 but the actual COP is 1.67 . The efficiency margin calculate with formula (10) is $37.2 \%$.

COP compararison - Simulation 2

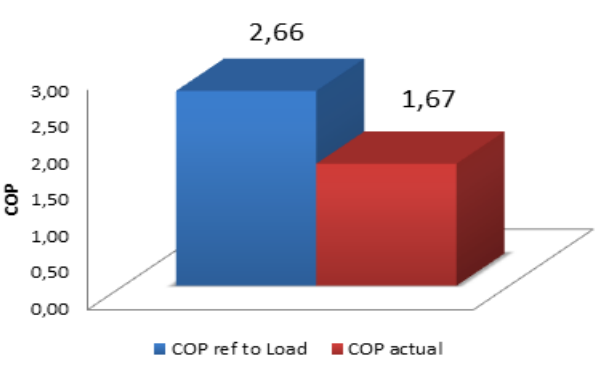

Fig. 20. Comparison of expected COP vs Actual COP at simulation 2

Table 2. Analysis result at Simulation 2

\begin{tabular}{|c|c|c|c|c|c|}
\hline $\begin{array}{l}\text { Time } \\
\text { (s) }\end{array}$ & $\begin{array}{l}\text { load } \\
\text { (watt) }\end{array}$ & $\begin{array}{l}\text { speed ref to } \\
\text { load (Rpm) }\end{array}$ & $\begin{array}{l}\text { Speed } \\
\text { executed } \\
\text { (Rpm) }\end{array}$ & $\begin{array}{l}\text { PI ref to } \\
\text { load (watt) }\end{array}$ & $\begin{array}{c}\text { PI } \\
\text { excecuted } \\
\text { (watt) }\end{array}$ \\
\hline 5 & 255 & 1687 & 1687 & 153 & 153 \\
\hline 10 & 255 & 1687 & 1687 & 153 & 153 \\
\hline 15 & 255 & 1687 & 1687 & 153 & 153 \\
\hline 20 & 190 & 1257 & 1562 & 63 & 122 \\
\hline 25 & 190 & 1257 & 1530 & 63 & 114 \\
\hline 30 & 154 & 1015 & 1531 & 33 & 114 \\
\hline 35 & 154 & 1015 & 1450 & 33 & 97 \\
\hline 40 & 154 & 1015 & 1428 & 33 & 93 \\
\hline 45 & 127 & 839 & 1427 & 19 & 93 \\
\hline 50 & 127 & 835 & 1525 & 19 & 113 \\
\hline 55 & 127 & 835 & 1529 & 19 & 114 \\
\hline 60 & 194 & 1283 & 1529 & 67 & 114 \\
\hline 65 & 194 & 1283 & 1594 & 67 & 129 \\
\hline 70 & 233 & 1541 & 1594 & 117 & 129 \\
\hline 75 & 233 & 1541 & 1594 & 117 & 129 \\
\hline 80 & 233 & 1541 & 1541 & 117 & 117 \\
\hline 85 & 220 & 1452 & 1479 & 98 & 103 \\
\hline 90 & 220 & 1452 & 1452 & 98 & 98 \\
\hline 95 & 206 & 1364 & 1405 & 81 & 88 \\
\hline 100 & 206 & 1364 & 1364 & 81 & 81 \\
\hline 105 & 100 & 666 & 1322 & 9 & 74 \\
\hline 110 & 100 & 666 & 1322 & 9 & 74 \\
\hline 115 & 100 & 666 & 1264 & 9 & 64 \\
\hline 120 & 87 & 578 & 1264 & 6 & 64 \\
\hline TOTAL & 4314 & & & 1619 & 2585 \\
\hline
\end{tabular}

\section{Conclusion}

Base on the data analysis, can be concluded as follows :

1. The increment of the energy efficiency in the chilled water pumping system can be achieved if the control valve system is operate in performance/normal condition.

2. The system efficiency is shown on the value of coefficient of performance (COP). In simulation 1 the COP is 1.07 with efficiency margin is $16.4 \%$. In simulation 2 the COP is 1.67 with efficiency margin is $37.2 \%$.

3. The thermomechanical method can increase the energy efficiency if the control valve system is in the normal condition. If the control valve system is failed/abnormal condition, the thermomechanical method can not give the energy efficiency as good as at the control valve at the normal condition. Nevertheless, thermomechanical method can increase the efficiency margin at the condition that the control valve system is under performance.

\section{Reference}

[1] ASHRAE Handbook Committee (2001). HVAC Fundamental Handbook. Atlanta: ASHRAE Publishing

[2] Ibrahim Al Bahadly. Energy Saving with Variable Speed Drive in Industry Applications: WSEAS Int. Conference on Circuits, Signal and Telecommunications, Australia, 2007, P $53-58$

[3] Ilja Bakman and Valery Vodovozov. Sensorless Pressure Control of Centrifugal Pumps, Compatibility and Power Electronic (CPE) 8th International Conference, IEEE, 2013, P $304-309$

[4] Herbert W. Stanford (2003). HVAC Water Chillers and Cooling Tower, Fundamental, Application and Operation. North Carolina : Marcel Dekker .Inc

[5] Levon Gevorkov, Valery Vodovozov, Tonu Lehtla and Zoja Raud. PLC Based Hardware in the Loop Simulator of a Centrifugal Pump, 5th International Conference on Power Engineering, 2015, IEEE, P 491 - 496

[6] Tarik Al Shemmeri (2010). Engineering Thermodynamics. Tarik Al Shemmeri \& Ventus Publishing ApS

[7] Mark W. Zemansky, Ph.D \& Richard H. Dittman (1997), $\mathrm{Ph} . \mathrm{D}$. Heat and Thermodynamics.Seventh Edition, New York : McGraw-Hill

[8] Xiaolong Li, Sairam Munigala, Qin An Zeng, Design and Implementation of a Wireless Programmable Logic Controller System, International Conference on Electrical and Control Engineering, 2010, IEEE, P 3138 - 3141

[9] Zhiguang GONG \& Xudong MENG. The Testing System of Thermal Performance of Heating Radiators Based on ZigBee Wireless Sensor Network Technology, Sensor \& Transducers, 2013, IFSA, Vol 158, pp 100 - 106

[10] Kartik Rathod, Nilay Parikh, Aesha Parikh, Prof. Vrushank Shah, Wireless Automation using Zigbee Protocols, Wireless and Optical Communication Network (WOCN), ninth International Conference, 2012, IEEE, P 1 - 5

[11] I.F. Akyildiz, W. Su, Y. Sankarasubramaniam, E. Cayirci. Wireless sensor networks: a survey, Computer Network 38, 2002, Elsevier, P 393 - 422

[12] Vehbi C. Gungor, Gerhard P.Hancke, Industrial Wireless Sensor Network : Challenge, Design Principles, and Technical Approaches, IEE Transaction on Industrial Electronic, Vol 56, no 10, October 2009.

[13] [14] Yuwono Marta Dinata (2015). Arduino itu Mudah. Jakarta: PT. Elex Media Komputindo.

[14] G. Hovstadius, V. Tutterow and S. Bolles, Getting it right. Applying a system approach to variable speed pumping, 4th International Conference on Energy Efficiency in Motor Driven Systems EEMODS 2005,Heidelberg, Germany, 2005.

[15] J. E. Finnemore and J B. Franzini, Fluid Mechanics with Engineering Applications, NY: McGraw Hill, Inc., 2002.

[16] Shan K. Wang, Handbook of Air Conditioning and Refrigeration, New York: McGraw Hill, Inc, 2001 